\title{
Macular microhole - a case report
}

\section{Jacques Ramos Houly*}

Department of Ophthalmology, Federal University of Minas Gerais, Brazil

Fundação Hilton Rocha, Minas Gerais, Brazil

\section{Introduction}

Macular microholes were first described in 1988 by Cairns and McCombe [1] and they are characterized by a small defect in the fovea, usually not exceeding $150 \mu \mathrm{m}$ in size. These lesions can affect one or both eyes and commonly they have a reddish appearance at biomicroscopy [2-4]. Unlike the full-thickness macular holes, in which there is a dehiscence of all retinal layers, macular microholes seem to affect only the deeper layers of the retina.

This clinical entity can affect both genders in any age group and its etiology has not yet been fully elucidated. Patients with microholes may be asymptomatic or have slight decrease of visual acuity with or without metamorphopsia and scotoma. Diagnosis of this disease is based on the findings of optical coherence tomography (OCT) [3-5].

\section{Case report}

A 36-year-old man presented to the Fundação Hilton Rocha, Brazil, for ophthalmologic examination with a vague history of visual disturbances in his right eye. He denied trauma, scotoma, metamorphopsia or previous episodes of phototoxicity. Additionally, there was no history of systemic diseases or use of medications. A complete ophthalmic examination was performed, including refractometry with measurement of visual acuity, applanation tonometry, biomicroscopy and binocular indirect ophthalmoscopy. On examination his best-corrected visual acuity was 20/50 in the right eye and 20/20 in the left eye. Anterior segment examination was unremarkable and intraocular pressure was normal. Fundoscopic examination revealed a normal optic disc with a small cup-to-disc ratio and a round red defect in the fovea of the right eye. Fundus photography of the left eye was normal (Figure 1).

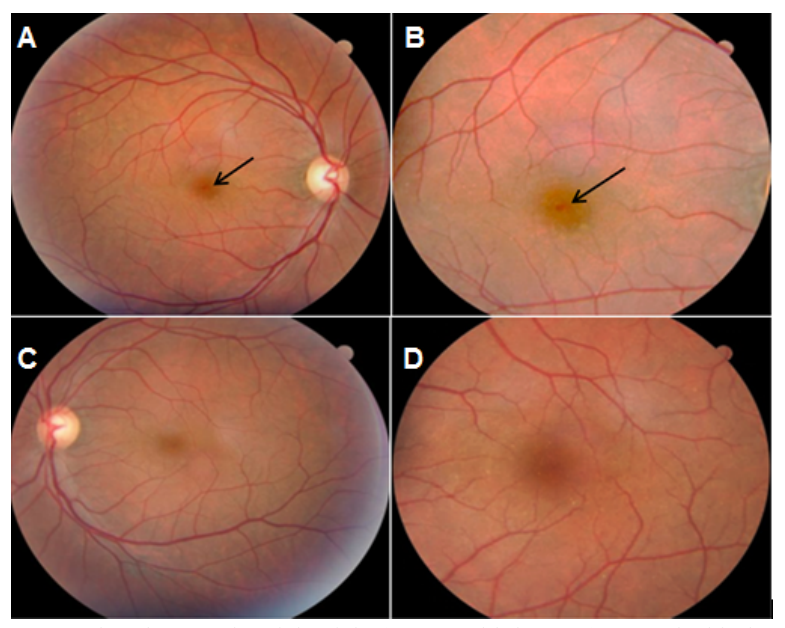

Figure 1. Fundus photographs of the right (A, B) and left eyes (C, D). The black arrows show the microhole in the right eye.
Fluorescein angiography of both eyes was normal (Figure 2). Optical coherence tomography revealed small defect of approximately $60 \mu \mathrm{m}$ in the outer retinal layers with disruption of ellipsoid and interdigitation zones (Figure 3).

\section{Discussion}

Macular microholes are characterized by a small retinal lamellar defect. They constitute an unusual nosological entity and have different biomicroscopic characteristics in comparison with idiopathic full-thickness macular holes. According to some authors, these lesions seem to have association with trauma and disorders of the

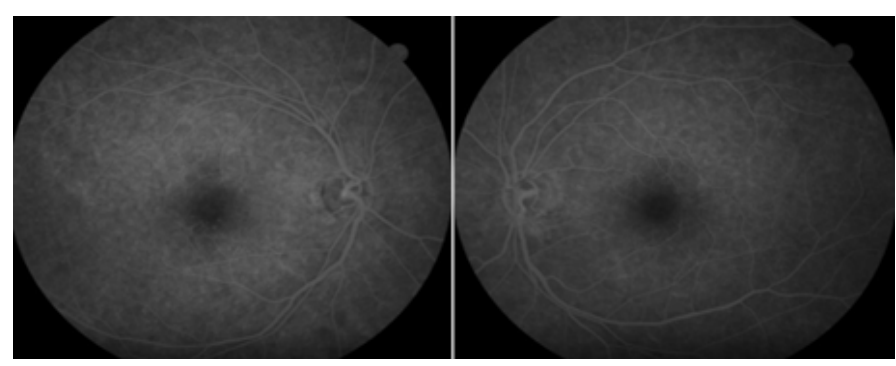

Figure 2. Fluorescein angiography does not reveal a transmission defect or other abnormality.

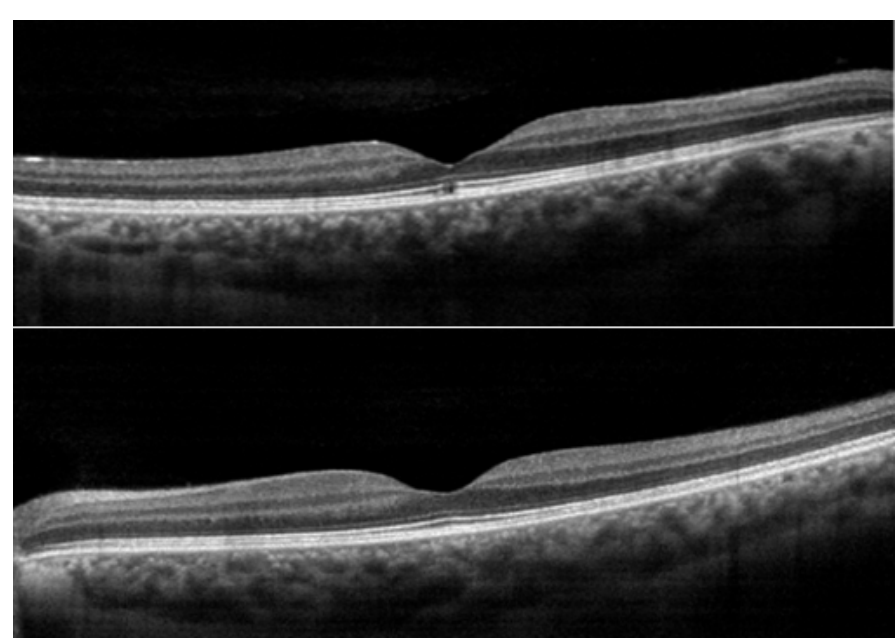

Figure 3. Spectral-domain OCT (horizontal scan) of the right eye (top) shows a small defect at outer retinal layers and intact foveal tissue in the left eye (bottom).

Correspondence to: Jacques Ramos Houly, Department of Ophthalmology, Federal University of Minas Gerais, Brazil, E-mail: jacquesramos@ig.com.br

Received: June 29, 2017; Accepted: July 27, 2017; Published: July 31, 2017 
vitreoretinal interface. One of the main differential diagnoses is the solar maculopathy [3]. Macula microholes may go unnoticed in the routine ophthalmological examination due to its small size and patients may be asymptomatic or have mild visual impairment, as described in this case. Symptoms such as scotoma, metamorphopsia, micro and macropsia were described by some authors $[3,5]$. As the macular microholes consist of discrete foveolar defects, fluorescein angiography may be normal due to the tenuous features of the retinal defect, as shown in this report. However, some authors have shown patients with hyperfluorescence at angiogram (window defect) [5].

Several studies have demonstrated the cumulative importance of OCT in the evaluation of macular microholes. Tomographic scanning is useful in determining the exact location of the retinal defect and this device is also able to measure the size of the lesion [3-5]. In this case report, definitive diagnosis was done through the spectral-domain OCT. As can be seen, the figure 3 reveals a small hyporreflective cystic defect located in the ellipsoid and interdigitation zones (previously known as the junction of the inner and outer photoreceptor segments and COST line, respectively).
As described in the literature, [3] macular microholes do not constitute an continuous risk for progression and full-thickness macular hole development. In this case report, the foveal defect remained stable during a long-term follow-up (26 months) with no tomographic or biomicroscopic changes. Due to this reason, there was no need for surgical intervention.

\section{References}

1. Cairns JD, McCombe MF (1988) Microholes of the fovea centralis. Aust $N Z J$ Ophthalmol 16: 75-79. [Crossref]

2. Reddy CV, Folk JC, Feist RM (1996) Microholes of the macula. Arch Ophthalmol 114: 413-416. [Crossref]

3. Zambarakji HJ, Schlottmann P, Tanner V, Assi A, Gregor ZJ (2005) Macular microholes: pathogenesis and natural history. Br J Ophthalmol 89: 189-193. [Crossref]

4. Emerson GG, Spencer GR, Klein ML (2007) Macular microholes. Retina 27: 595-600 [Crossref]

5. Novelli FJ, Maia OO Jr, Nóbrega MJ, Garrido Neto T, Takahashi WY (2009) [Clinical and tomographic aspects of macular microholes]. Arq Bras Oftalmol 72: 33-38. [Crossref]

Copyright: $\odot 2017$ Houly JR. This is an open-access article distributed under the terms of the Creative Commons Attribution License, which permits unrestricted use, distribution, and reproduction in any medium, provided the original author and source are credited. 